\title{
Molecular Characterization of Bacillus-Genus Bacteria with Fibrinolytic Potential Isolated from Squashes «NTETE» in Brazzaville in the Republic of Congo
}

\author{
Faly Armel SolokaMabika ${ }^{1,2}$, Etienne Nguimbi ${ }^{1,2,3, *}$, Aimé Christian Kayath ${ }^{1,3}$, Gabriel Ahombo ${ }^{1,2}$ \\ ${ }^{1}$ Laboratoire de Biologie Cellulaire et Moléculaire, Faculté des Sciences et Techniques, Université Marien Ngouabi \\ ${ }^{2}$ Unité de Biologie moléculaire et Bioinformatique, Faculté des Sciences et Techniques, Université Marien Ngouabi \\ ${ }^{3}$ Institut de Recherche en Sciences Naturelles et Exactes (IRSEN) \\ *Corresponding author: etienne.ng1612@gmail.com
}

Received December 20, 2019; Revised February 03, 2020; Accepted February 20, 2020

\begin{abstract}
Thromboses appearing in the blood and causing cardiovascular disease by the presence of fibrin remain a problem of concern worldwide. The fibrinolytic enzymes developed by bacteria of the Bacillus-genus are today an interesting and promising alternative to chemicals with multiple consequences. It is in this perspective that three (3) samples of cooked squash wrapped in sheets and consumed in Brazzaville and collected and in three Brazzaville markets were explored. The estimated count of the total flora of each sample for each of the three markets, namely Total, Moukondo and Tsiémé was carried out on PCA and represents respectively $(5.2 \pm 0.12) 107$ CFU / g, (1.73 \pm $0,16) 107 \mathrm{CFU} / \mathrm{g}$, and $(9.43 \pm 1.06) 107 \mathrm{CFU} / \mathrm{g}$ while bacteria of the genus Bacillus are estimated in Mossel respectively at $(3.5 \pm 1.16) 106 \mathrm{CFU} / \mathrm{g},(4,01 \pm 0.85) 106 \mathrm{CFU} / \mathrm{g}(8.96 \pm 0.60) 106 \mathrm{CFU} / \mathrm{g}$. Sixty-six isolates of bacteria of the genus Bacillus isolated from squash by conventional microbiology techniques have been phenotypically characterized. The morphological types characterized are essentially the bacillary form and the spherical form. The ability to produce fibrinolytic enzymes correlated with growth was assessed. The growth in terms of optical density varies from 0.800 to 0.97 and the enzymatic production in all the isolates tested varies from 12 to $21 \mathrm{~mm}$. After DNA extraction from 36 isolates, PCR amplification of the rR16S gene revealed fragments of approximately 1500bp by electrophoresis on Agarose Gel. The sequencing of thirty-four (34) fragments made it possible to obtain fifteen (15) sequences having a strong similarity between them and also with the homologs of the databases (97\% to 100\%) and therefore the molecular identification of: Bacillus sp 40\%, Bacillus amyloliquefaciens 6.66\%, Bacillus subtilis 33.33\%, Bacillus Pumilus 6.66\%, Bacillus megaterum 6.66\%, Bacillus velezensis 6.66\%. Five (5) of these sequences have been submitted to GenBank and the accession numbers are successively: MK193815.1 (Bacillus subtilis strain ASM1), MK207434.1 (Bacillus subtilis strain ASM3), MK207435.1 (Bacillus pumilus strain ASM5), MK207436.1 (Bacillus subtilis strain ASM4), MK207437.1 (Bacillus megaterium strain ASM2).The multiple alignment of sequences obtained shows a high conservation of this gene in bacteria of the genus Bacillus. The phylogenetic classification clearly shows this monophyletic class of bacteria of the genus Bacillus with very short distances(less than 3\%).
\end{abstract}

Keywords: molecular characterization, fibrinolytic potential, Bacillus, squash, Brazzaville

Cite This Article: Faly Armel SolokaMabika, Etienne Nguimbi, Aimé Christian Kayath, and Gabriel Ahombo, "Molecular Characterization of Bacillus-Genus Bacteria with Fibrinolytic Potential Isolated from Squashes «NTETE» in Brazzaville in the Republic of Congo." American Journal of Microbiological Research, vol. 8, no. 1 (2020): 7-18. doi: 10.12691/ajmr-8-1-2.

\section{Introduction}

In recent years the idea of a direct relationship between an optimal diet and a healthy lifestyle has gained ground among the general public. Thus, healthy food markets have developed strongly in order to meet the demand of consumers who increasingly seek to control their quality of life and their state of health through better nutrition [1]. These foods are either subjected to transformation processes under the influence of microorganisms in the case of fermented foods or undergo no transformation in the case of non-fermented foods. Ntete is a food product obtained from the seeds of squash (cucurbitaceae). Squash is an ornamental and vegetable plant, with a long climbing stem and large orange flowers belonging to the cucurbitaceae family, of which there are roughly 100 genera and 750 species listed worldwide. This family is known for its great genetic diversity and its great adaptation to tropical, subtropical regions.They are particularly cultivated in the departments of Pool, Bouenza and Plateaux for their seeds and leaves for food and medicinal purposes (In traditional pharmacopoeia). In 
Congo Brazzaville, according to the vernacular languages, cucurbitaceae have different names: Nta in Téké, Bibete in Lari, EtiereouNdzeyi in Mbochi, Mbika in Lingala, Ntete in Kituba, Mbindzi or Bikokoto in Bembe, Ndzeki in TékéAlima, Téri in Pounou ,Nzaka in Nzabi, Tiété (Tékéyaya) in Niari.

Ntete in the vernacular (Kituba) is produced consumed practically throughout Africa where they are tasted in salads but also stuffed or breaded. The flesh of the squash is used in several meals such as soups, gratins, purees, quiches but also in sweet desserts, flans, pies, cakes, jams or even chutney, in bread doughs and cakes after baking. To date, no studies have been performed on the microbial flora of this food. Previous work has already shown that fermented foods are ecological niches for many microorganisms such as the genus Bacillus. The genus Bacillus is part of the phylum of Firmicutes, of the class Bacilli, of the order Bacillales, and of the family Bacillaceae. $[2,3]$. These are Gram positive bacteria, capable of living under aerobic and anaerobic conditions [4]. The genus Bacillus represents a heterogeneous group of bacteria, and by the diversity of their applications, these bacteria represent one of the largest groups producing industrial enzymes. Bacillus subtilis, Bacillusamyloliquefaciens and Bacillus licheniformis are three species of colossal commercial interest [5].

Bacillus bacteria isolated from fermented or unfermented foods produce proteolytic enzymes, notably fibrinolytic enzymes which are of great medical interest [6]. In this work we isolated, phenotypically characterized and identified using 16S rRNA bacteria of the genus Bacillus from squash packed on the leaves, cooked and consumed in Congo. We then tested the capacity of these bacteria to producing fibrinolytic enzymes, the phylogenetic classification of these bacteria was also analyzed.

\section{Materials and Methods}

\subsection{Samples Collection, Culture Conditions and Counting}

The squash samples are represented by Ntété (squash commonly known in Congo Brazzaville NTETE wrapped in leaves and cooked in a smothered state). Our samples were bought in the different markets of Brazzaville. Three (3) markets were targeted:

- Total market located in the south of the city of Brazzaville

- Moukondomarketlocated more less in the center of the city

- Tsièmé market located in the northern area of the city

In a test tube containing $9 \mathrm{ml}$ of distilled water, $1 \mathrm{~g}$ of squash was added constituting the mother solution from which the decimal dilutions were made. The inoculations were made on petri dishes in two culture media, PCA (for the enumeration of total microorganisms) and Mossel (for the enumeration of bacteria of the genus Bacillus). The dishes were incubated at $37^{\circ} \mathrm{C}$. for $24 \mathrm{~h}$ in an aerobic oven. After appearance of the colonies, the counting is carried out and the counting carried out the followingformula [7]:

$$
U F C=N / V D
$$

$\mathrm{CFU} / \mathrm{g}=$ Colony Forming unit, $\mathrm{N}=$ number of colonies, $\mathrm{V}=$ used volume of plating, $\mathrm{D}=$ dilution factor.

\subsection{Colony Purification of and Isolation}

Purification is one of the most important steps in isolating strains. It was made in a nutritive agar. Each colony was sown separately with streaks until very distinct and homogeneous colonies were obtained. To ensure the purity of the strains, a microscopic observation was carried out [8]. The isolates were stored in cryotubes containing the appropriate broth (LB) added with $20 \%$ glycerol (v/ v) and refrigerated at $4{ }^{\circ} \mathrm{C}$. Only suspected Bacillus isolates have been retained

\subsection{Phenotypic Characterization of Isolates}

The characterization of the isolates was started by the application of classical microbiology techniques, based on the search for a certain number of phenotypic characters (colony morphology, cell morphology, Gram type and catalase production). All these characterization techniques have been previously described by $[9,10]$. Before use, the stored isolates are subcultured on an appropriate agar incubated at $37{ }^{\circ} \mathrm{C}$ for 24 hours.

\subsection{Study of the Proteolytic Potential of Some Isolates}

\subsubsection{Proteolytic Enzyme Production}

To test the production of the caseinolytic enzyme, we used the techniques used by modified [11]. The cells were cultured in LB medium with stirring at $37{ }^{\circ} \mathrm{C}$., 48 hours after culture the medium was centrifuged and the supernatant recovered. In a $250 \mathrm{ml}$ Erlenmeyer flask containing $100 \mathrm{ml}$ of $0.1 \mathrm{~N}$ PBS, dissolve $1 \mathrm{~g}$ of agarose, heat until completely dissolved, allow to cool to $55-60{ }^{\circ} \mathrm{C}$, add $10 \mathrm{ml}$ of skimmed milk, homogenize the mixture. Pour into the Petri dishes; after solidification, prepare wells in the gel. Place $50 \mu$ l of supernatant from the culture centrifugation in each well. Place the boxes in the oven at $37{ }^{\circ} \mathrm{C}$ for 12 hours. Observation of a clear translucent zone indicates that the strain produces a proteolytic enzyme with caseinolytic effect (caseinolytic protease) $[12,13]$.

\subsubsection{Fibrinolytic Enzyme Production}

The fibrinolytic production was evaluated by enzymatic assay. The fibrinolytic activity was determined by the modified fibrin dish method [14]. The supernatant of the appropriate growth stage of Bacillus cells was used. Briefly; $25 \mathrm{ml}$ of a solution $0.5 \%$ fibrin was mixed with $25 \mathrm{ml} 1 \%$ agarose gel in a petri dish and placed for 30 minutes at room temperature Holes were made on the plate $20 \mu \mathrm{l}$ of sample were added to each set and the plate was incubated at $37{ }^{\circ} \mathrm{C}$ for 16 hours. Fibrinolytic activity was measured by the lytic area across the diameter of the clear area. The diameter of the clear area was measured and used to assess enzyme production $([12,13,14,15]$. 


\subsubsection{Evaluation of Growth of Isolates}

During the culture of the isolates for the production of proteolytic enzyme, the culture solution was centrifuged and the supernatant was used to measure the optical density or (OD) with a spectrophotometer of the ZUZI type, three measurements of the OD for three cultures different from $\mathrm{mm}$ isolates determined the means used to plot the growth curves

\subsection{Molecular Identification of Isolates}

The identification of strains by phenotypic methods does not allow reliable identification of the different species [9]. The purified isolates were subjected to a PCR of their $16 \mathrm{~S}$ rDNA and sequencing, this allows identification more precisely.

\subsubsection{Extraction of Genomic DNA}

The extraction of genomic DNA by the NucleoSpin kit was carried out as indicated by the manufacturer, below summarized.

A fresh culture of the strain was suspended in $1 \mathrm{ml}$ of LB, we then centrifuged at 10,000 rpm for 4 minutes at 4 ${ }^{\circ} \mathrm{C}$ using a centrifuge of the Micro Star 17R type; The pellet was mixed with $100 \mu$ of 'Elution Buffer BE, the cell suspension was transferred to a Type B Nucleo Spin Bead Tube contained in the kit, then $40 \mu \mathrm{l}$ of Buffer MG and $10 \mu \mathrm{l}$ of Liquid Proteinase $\mathrm{K}$ were added and the tube was closed. Back and forth movement movements were made for 12 minutes. After centrifugation at $10,000 \mathrm{rpm}$ for 1 minute was started. After centrifuging, $600 \mu \mathrm{l}$ of Buffer MG added and we vortexed for 3 seconds; the tubes were centrifuged at 10,000 rpm for 1 minute. The supernatant was transferred to the Nucleo Spin Microbial DNA Column placed in the $2 \mathrm{ml}$ Tube Collection, after having transferred the supernatant, the tubes were centrifuged at $10,000 \mathrm{rpm}$ for 1 minute. The Collection Tube containing the liquid collected is discarded and the Nucleo Spin Microbial DNA Column was replaced in a new Collection Tube of $2 \mathrm{ml}$, a first washing was carried out by adding $500 \mu \mathrm{l}$ of Buffer BW and the tubes were then centrifuged at $10,000 \mathrm{rpm}$ for 1 minute, after centrifugation, the tubes were placed in a new $2 \mathrm{ml}$ Tube Collection. A second washing was carried out with $500 \mu \mathrm{l}$ of Buffer B5 and the tubes were centrifuged at 10,000 rpm for 1 minute, The Collection Tube containing the collected liquid were discarded and the Nucleo Spin Microbial DNA Column was replaced in a new Collection Tube then centrifugation at 10,000 rpm for 1 minute, vacuum was started. The Nucleo Spin Microbial DNA Column were placed in the sterile Eppendorf tubes and $100 \mu$ of Buffer $\mathrm{BE}$ were added, we then incubated at room temperature for 1 minute, after incubation, the tubes were centrifuged at $10,000 \mathrm{rpm}$ for 1 minute.

\subsubsection{PCR Amplification of Genes Encoding 16S rRNA}

\subsubsection{Designation of Primers}

The gene coding for $16 \mathrm{~S}$ rRNA is a molecular marker widely used for the molecular identification of bacteria, indeed it is very conserved. We used universal primers to amplify the genes coding for RNA ribosomal 16S [16].
Table 1. Universal primers of 16S rRNA gene used in thisstudy

\begin{tabular}{|c|c|c|}
\hline Primers & Primer sequences & Reference \\
\hline UF & (5'-AGA GTT TGA TCC TGG CTC AG-3') & \\
\hline UR & (5'-ACG GCT ACC TTG TTA CGA CTT-3') & \\
\hline
\end{tabular}

\subsubsection{Composition of the Mix and PCR Conditions}

The PCR reaction was carried out in a final volume of $50 \mu \mathrm{L}$ containing $32.75 \mu \mathrm{L}$ of sterile distilled water, $2 \mu \mathrm{L}$ of DNA, $2 \mu \mathrm{L}$ of each sense and antisense primers, $1 \mu \mathrm{l}$ of dNTP, $10 \mu \mathrm{L}$ of buffer and $0.25 \mu \mathrm{L}$ of Taq polymerase enzyme.

The PCR amplification was carried out in a type thermocycler (Bio - Rad) according to the following steps: first initial denaturation at $95^{\circ} \mathrm{C}$ for $5 \mathrm{~min}$. 30 cycles for each of thefollowing steps; denaturation at $95{ }^{\circ} \mathrm{C}$ for 30 seconds, hybridization is done at $55^{\circ} \mathrm{C}$ for 30 seconds, initial elongation at $72{ }^{\circ} \mathrm{C}$ for 1 minute 30 seconds, and a final elongation at $72{ }^{\circ} \mathrm{C}$ for 5 minutes [16]. PCR products were visualized by agarose gel electrophoresis

\subsection{Agarose Gel Electrophoresis of PCR Products}

DNA samples are deposited in an agarose gel immersed in a TBE buffer (Tris-Borate-EDTA) $\mathrm{pH} 8.3$ and allowed to migrate under the effect of an electric field (DNA is a polyanion). DNA is visualized by adding midori (DNA dye which fluoresces by being inserted between the DNA bases). The speed depends on the size of the DNA molecule. A size marker is used to determine the size of the fragments. The concentration of the gel to be prepared depends on the size of the gene to be visualized. $0.8 \%$ Agarose Gel was used. The DNA samples were processed before they were placed in the wells. For this, we used the Midori and Buffer Dye. 5 microliters of PCR Productswere mixed with 0.5 microliter of midori and 1 microliter of Buffer Dye. The tank was previously filled with TBE buffer solution so that the gel is completely immersed in the buffer. The gel was subjected at a voltage of $100 \mathrm{~V}$ for one hour. The gel was visualized under a UV lamp, by fluorescence

\subsection{Sequencing of PCR Products}

The classical PCR products positive for the $16 \mathrm{~S}$ genes were purified using the NucleoFast 96 PCR plate (Macherey-Nagel EURL, France) and sequenced using the BigDye terminator chemistry on an ABI3730 sequencer (Applied Biosystems, Foster City, California, United States). The sequencing was carried out by electrophoresis on a DNA analyzer 3730xl-Titania (Applied Biosystems) using the same primers as those used for the amplification by PCR of the genes coding for the $16 \mathrm{~S}$ rRNA.

\subsection{Analysis of Results}

\subsubsection{Statistical Analysis}

We used Excel for the statistical analyzes, also to make databases and draw the graphs related to the evaluation of the growth and the enzyme production. 


\subsubsection{In-Silico Analysis of Sequencesof Isolates}

The sequences obtained were assembled using two software programs (DNA Baser assembler and Codon Code Aligner) and the results were compared for reasons of reliability. Sequence analysis was carried out using the basic local alignment search tool (BLAST) available on the website of the national database, biotechnology information center (http: // www.ncbi.nlm.nih.gov). The translation of the nucleotide sequences into protein sequences was carried out on SMS ORF Finder. The protein sequences were aligned on CrustalW and by MEGA

BLAST a family of five programs that allow the alignment of a new sequence with respect to a database. This consists in comparing this request sequence with the genomes existing in the databases in order to detect the homologous sequences there. Statistical tests make it possible to decide whether the alignment obtained is significant and the results provided are classified in order of reliability [17].

The BLAST program uses the algorithm developed by [18] to search for similar segments between a query sequence (or "query" sequence) and all of the sequences present in the nucleic or protein bank. The sequences are classified according to a "score" which depends on the homology with the request sequence, the size of the bank and the value of the "E-Value". The smaller it is, the greater the homology between the request sequence and that of the bank [17].

\section{Determination of the bacterial species}

After BLASTn analysis of the nucleotide sequences, the identification of the genus or species is carried out according to the following criteria $[19,20]$.

- If the comparison of the sequence obtained with a sequence of a classified reference species yielded percentages of similarity $\geq 99 \%$, the unknown isolate will be assigned to this species;

- If the percentages are between $97 \%$ and $99 \%$ the unknown isolate will be assigned to the corresponding genus;

- If the percentages are $\leq 97 \%$, the unknown isolate will be assigned to a family.

Phylogenetic and molecular evolutionary analyzes were carried out using MEGA version 7 [21].

\section{Results}

\subsection{Enumeration}

Table 2 below shows the enumeration of microorganisms. The total flora is enumerated on the PCA, bacteria of the genus Bacillus are enumerated on Mossel medium.

This table shows that both for the total flora and for bacteria of the genus Bacillus the microbial mass varies from one sample to another. For the total flora, the most important microbial mass is found in the squash samples from the Tsiémé market. As well as bacteria of the genus Bacillus.

\subsection{Phenotypic Characterization of Isolates}

Only the strains isolated from the Mossel medium were retained for the rest of this work. A total of 60 isolates were characterized. The microscopic examination made it possible to distinguish variable characteristics. Two forms of bacteria have been characterized, Cocci and rods. Rod shapes are more abundant than spherical shapes. They are predominantly gram positive, although some gram negative bacteria have been found, catalase positive and negative.

Table 2. Enumeration of microorganisms in the different squash samples

\begin{tabular}{|c|c|c|c|}
\hline \multirow{2}{*}{ Mediums } & \multicolumn{3}{|c|}{ Samples } \\
\cline { 2 - 4 } & Total market & Moukondo market & \\
\cline { 2 - 4 } & $(3,5 \pm 1,16) 10^{6} \mathrm{UFC} / \mathrm{g}$ & $(4,01 \pm 0,85) 10^{6} \mathrm{UFC} / \mathrm{g}$ & $(8,96 \pm 0,60) 10^{6} \mathrm{UFC} / \mathrm{g}$ \\
\hline Mossel & $(5,2 \pm 0,12) 10^{7} \mathrm{UFC} / \mathrm{g}$ & $(1,73 \pm 0,16) 10^{7} \mathrm{UFC} / \mathrm{g}$ & $(9,43 \pm 1,06) 10^{7} \mathrm{UFC} / \mathrm{g}$ \\
\hline
\end{tabular}

Table 3. Phenotypic characteristics of the isolates

\begin{tabular}{|c|c|c|c|c|c|c|}
\hline Sample & Strain code & Bacterial form & Test of KOH à $\mathbf{3 \%}$ & Test of catalase & Mobility & Sporulation \\
\hline \multirow{18}{*}{$\mathbf{O}_{5}$} & $\mathrm{SPO}_{5} 1$ & Bacille & + & + & + & - \\
\hline & $\mathrm{SPO}_{5} 2$ & Bacillus & - & + & + & + \\
\hline & $\mathrm{SPO}_{5} 3$ & Bacillus & - & + & + & + \\
\hline & $\mathrm{SPO}_{5} 4$ & Bacillus & - & + & + & + \\
\hline & $\mathrm{SPO}_{5} 5$ & Bacillus & - & + & - & + \\
\hline & $\mathrm{SPO}_{5} 6$ & Bacillus & - & + & - & - \\
\hline & $\mathrm{SPO}_{5} 7$ & Bacillus & - & + & + & + \\
\hline & $\mathrm{SPO}_{5} 8$ & Bacillus & - & + & - & - \\
\hline & $\mathrm{SPO}_{5} 9$ & Bacillus & - & + & + & + \\
\hline & $\mathrm{SPO}_{5} 10$ & Bacillus & - & + & - & + \\
\hline & $\mathrm{SPO}_{5} 11$ & Bacillus & - & - & + & + \\
\hline & $\mathrm{SPO}_{5} 11^{\prime}$ & Bacillus & - & + & + & + \\
\hline & $\mathrm{SPO}_{5} 12$ & Bacillus & - & + & + & + \\
\hline & $\mathrm{SPO}_{5} 13$ & Bacillus & - & + & + & + \\
\hline & $\mathrm{SPO}_{5} 14$ & Bacillus & - & + & + & + \\
\hline & $\mathrm{SPO}_{5} 14^{\prime}$ & Bacillus & - & + & - & + \\
\hline & $\mathrm{SPO}_{5} 16$ & Bacillus & - & + & - & + \\
\hline & $\mathrm{SPO}_{5} 17$ & Bacillus & - & + & + & + \\
\hline
\end{tabular}




\begin{tabular}{|c|c|c|c|c|c|c|}
\hline $\mathrm{SPO}_{5} 1 \xi$ & \multicolumn{2}{|c|}{ Bacillus } & \multirow{2}{*}{-} & \multirow{2}{*}{+} & \multirow{2}{*}{-} & \multirow{2}{*}{+} \\
\hline \multirow{8}{*}{$\mathrm{SPO}_{2}$} & $\mathrm{SPO}_{2} 1$ & Cocci & & & & \\
\hline & $\mathrm{SPO}_{2} 2$ & Bacillus & - & + & + & + \\
\hline & $\mathrm{SPO}_{2} 3$ & Bacillus & - & + & + & + \\
\hline & $\mathrm{SPO}_{2} 5$ & Bacillus & - & + & - & + \\
\hline & $\mathrm{SPO}_{2} 6$ & Cocci & + & - & - & - \\
\hline & $\mathrm{SPO}_{2} 7$ & Cocci & - & + & + & - \\
\hline & $\mathrm{SPO}_{2} 9$ & Bacillus & - & + & - & + \\
\hline & $\mathrm{SPO}_{2} 10$ & Bacillus & - & + & - & + \\
\hline \multirow{7}{*}{$\mathbf{T}_{1-2}$} & $\mathrm{~T}_{1-2} 1$ & Bacillus & - & + & + & + \\
\hline & $\mathrm{T}_{1-2} 2$ & Bacillus & - & + & - & + \\
\hline & $\mathrm{T}_{1-2} 3$ & cocci & - & + & - & - \\
\hline & $\mathrm{T}_{1-2} 4$ & cocci & - & + & - & - \\
\hline & $\mathrm{T}_{1-2} 5$ & Cocci inchain & - & + & - & - \\
\hline & $T_{1-2} 6$ & Cocci en chain & - & - & - & + \\
\hline & $\mathrm{T}_{1-2} 7$ & Bacillus & - & + & + & + \\
\hline Sample & Strain code & bactérialform & Test of KOH à 3\% & Test of catalase & Mobility & Sporulation \\
\hline \multirow{8}{*}{$\begin{array}{c}\text { Sampleof Moukondo } \\
\text { market }\end{array}$} & CMK 1 & rod & - & + & + & + \\
\hline & CMK 2 & rod & + & + & - & + \\
\hline & CMK 3 & Cocci & + & - & - & - \\
\hline & CMK 4 & rod & - & + & - & + \\
\hline & CMK 5 & Cocci & - & + & + & - \\
\hline & CMK 6 & Cocci & - & + & - & - \\
\hline & CMK 7 & rod & - & + & - & - \\
\hline & CMK 8 & rod & + & + & - & + \\
\hline \multirow{18}{*}{$\begin{array}{c}\text { Sample of } \\
\text { Total market }\end{array}$} & CMT 1 & Cocci & + & - & - & - \\
\hline & CMT 2 & rod & - & + & - & - \\
\hline & CMT 3 & rod & - & + & - & + \\
\hline & CMT 4 & rod & + & + & + & + \\
\hline & CMT 5 & rod & - & + & - & \\
\hline & CMT 7 & Cocci & - & + & - & - \\
\hline & СMT 9 & rod & - & + & - & \\
\hline & CMS 1 & Bacillus & - & + & - & + \\
\hline & CMS 2 & Bacillus & - & + & - & - \\
\hline & CMS 3 & Cocci & + & + & - & + \\
\hline & CMS 4 & Bacillus & - & - & - & + \\
\hline & CMS 5 & Bacillus & - & + & - & + \\
\hline & CMS 6 & Bacillus & - & + & - & + \\
\hline & CMS 7 & Bacillus & - & - & - & + \\
\hline & CMS 8 & Bacillus & - & + & & + \\
\hline & CMS 9 & Bacillus & & & & + \\
\hline & CMS 10 & Bacillus & - & + & - & + \\
\hline & CMS 11 & Cocci & - & + & - & - \\
\hline
\end{tabular}

\subsection{Storage of Isolates}

A total of 45 isolates were kept from all samples. The respective number of isolates kept per sample is as follows: 26 isolates for samples from the total market, 5 isolates for samples purchased from the Moukondo market and 14 isolates obtained for samples from the Tsièmé market.

\subsection{Proteolytic and Fibrinolytic Enzyme Production by the Isolates}

\subsubsection{Demonstration of Proteolytic and Fibrinolytic Enzymes Production}

Figure 1 below shows that the isolates were found to be strongly proteolytic by giving a broad, clear and very visible halo, the size or diameter of the halos is variable. The translucent spot is used as an indicator of the production of the proteolytic enzyme

\subsubsection{Evaluation of the Production of Proteolytic Enzyme}

Here the evaluation of the production of proteolytic enzyme is made simultaneously with the growth, the growth is expressed by the OD and the production of enzyme in diameter of the clear halo.

Figure 2 shows the optical densities of the different isolates of bacteria of the genus Bacillus isolated from squash. Note that the values of optical densities vary from one strain to another. The ASM1 strain followed by SPO14 and SPO14 'show the best growth.

Figure 3 shows the production of proteolytic enzymes from squash strains. The production is observed in all the Bacillus strains used with the exception of the strain K12 (negative control). The production of enzymes is higher in CRK, followed by CMS2 and ASM5, SPO5 15 and CMS8. The smaller enzymatic production is in CMS 12 and SPO2 5. 


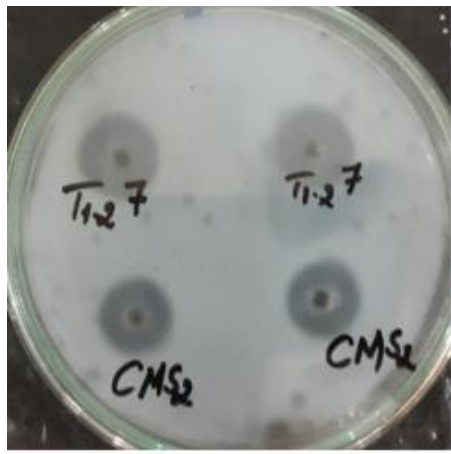

$\mathbf{A}$

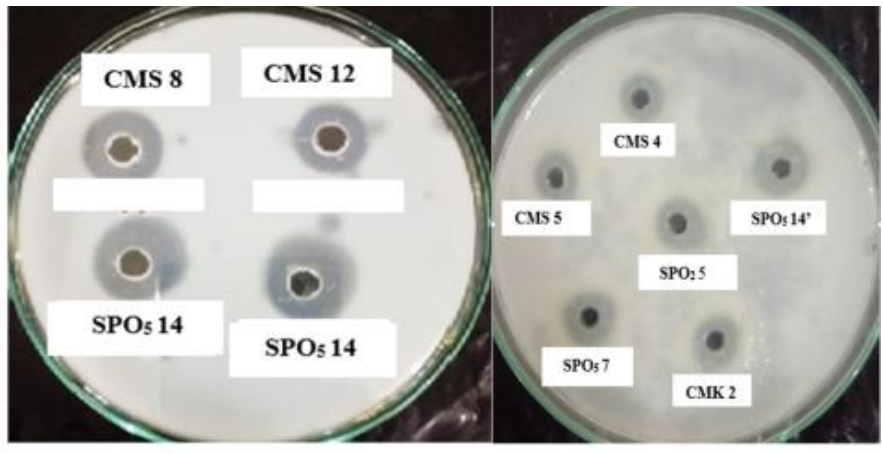

B

C

Figure 1. Proteolytic halo of different isolates(A with fibrine B and C with casein)

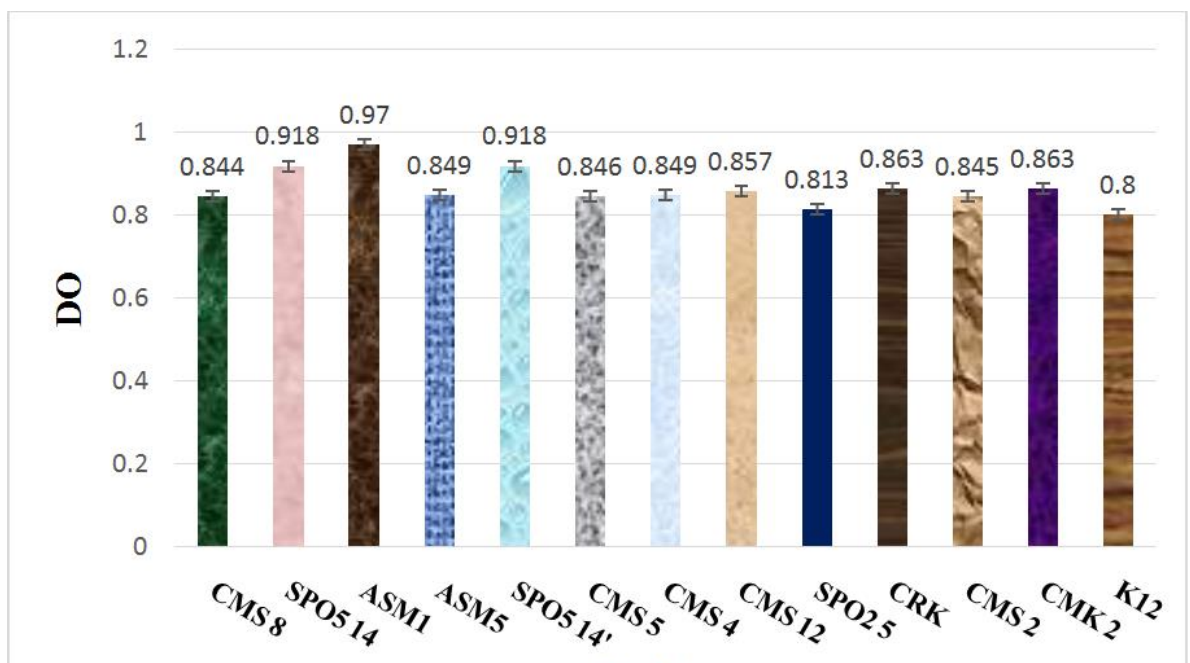

Isolats

Figure 2. Profile of Optical Densities (OD) of the different isolatesof squash.

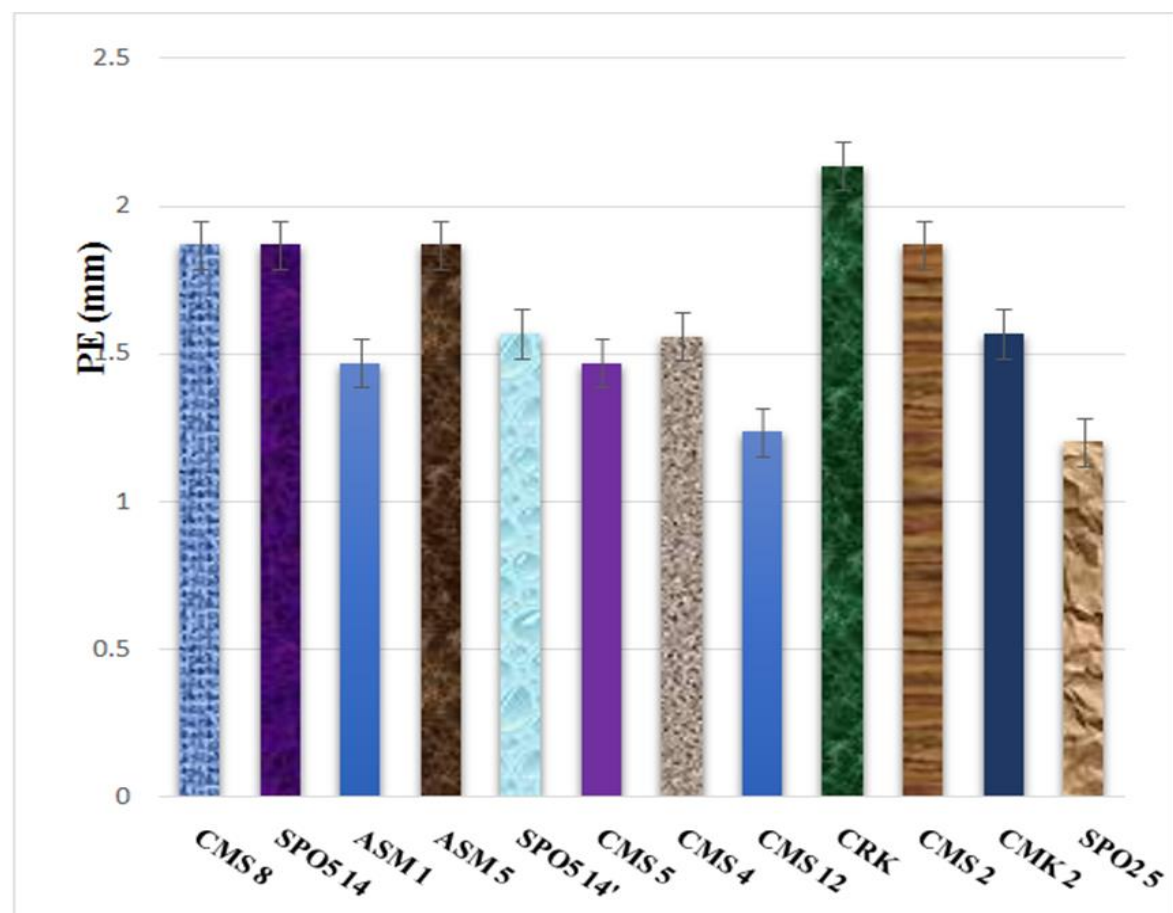

\section{Isolates}

Figure 3. Histogram of the enzymatic production of the different isolates of squash (Casein) 


\subsection{Molecular Identification of Isolates}

Isolates with proven proteolytic and fibrinolytic enzyme production by hydrolyzing fibrin and casein were identified by $16 \mathrm{~S}$ rDNA PCR and sequencing

\subsubsection{Agarose Gel Electrophoresis to PCR Products of Genes Coding for 16S Rrna in Isolates}

Figure 4 shows the electrophoresis of the 16S gene PCR products, each isolate has a DNA band of approximately $1500 \mathrm{bp}$.

From S1 to S36 are the DNA bands of the different isolates of squash
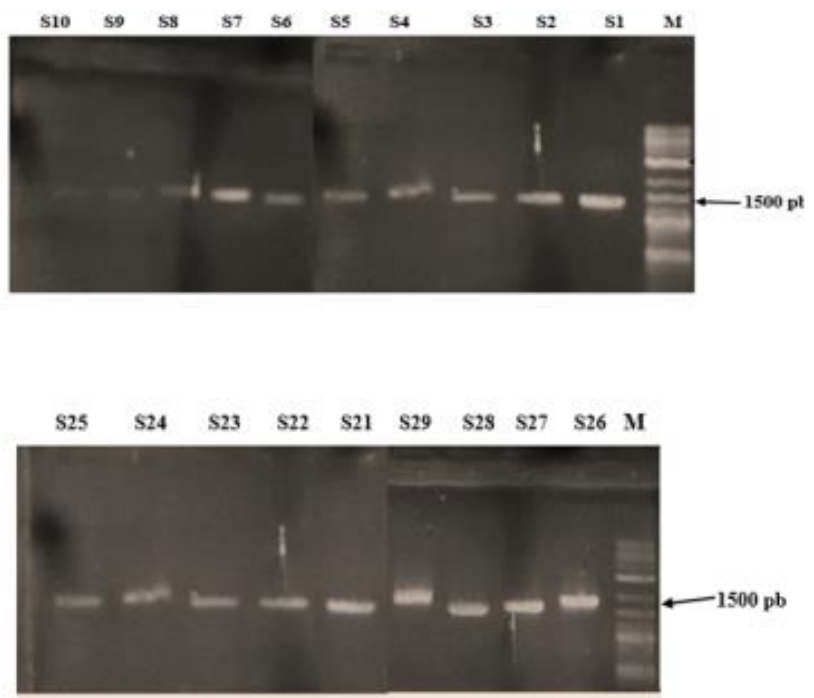

M: 2-log DNA ladder size molecular marker

\subsubsection{Results of the BLASTn Bioinformatics Analysis of the Nucleotide Sequences of the 16S rRNA Genes of Isolates Having Fibrinolytic Activity}

We used Blatn results for the identification via NCBI / GenBank isolates of squash for the rRNA16S gene. Different parameters of Blast such as Max score, Total Score, E. value and the percentage of similarity were used to identify the equivalent of the query strain in Gen Bank with the accession numbers Table 4 is showing the identification of the isolate according to the sequencing Code.

Except the Bacillus $s p$ with the similarity at $95 \%$ the genus, all percentage similarities are comprise between 97\%-100\%.Fifteen bacteria of Bacillus-genus have been identified by the 16SrRNA gene sequencing.
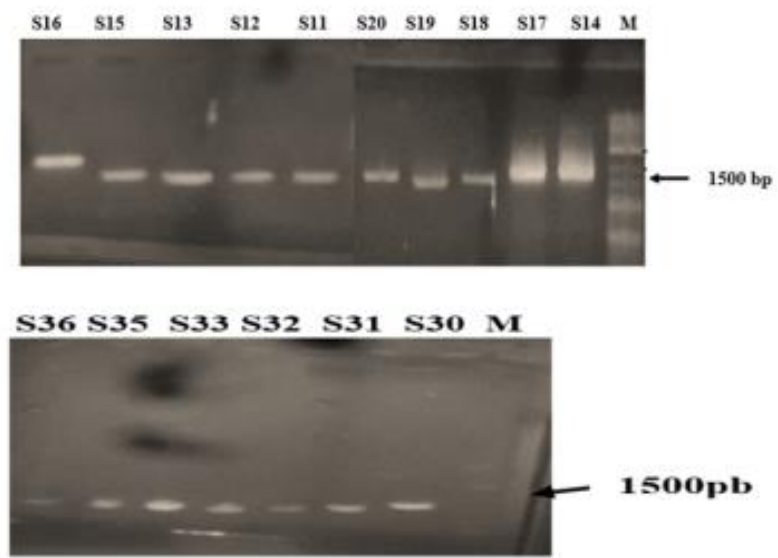

Figure 4. $0.8 \%$ Agarose gel electrophoresis of the PCR products obtained after amplification of the gene encoding 16S rRNA.

Table 4. Correspondence between the codes of the working isolates, the sequencing code and the strains identified by the rRr16S.

\begin{tabular}{|c|c|c|}
\hline isolates Code & $\begin{array}{c}\text { Sequençing Code \% of similarity } \\
\text { With the Equivalent } \\
\text { In GenBank }\end{array}$ & Identification \\
\hline $\mathrm{SPO}_{5} 12$ & $2995 \%$ & Bacillus Sp ASM55 \\
\hline $\mathrm{SPO}_{5} 4$ & $4 \quad 95,52 \%$ & Bacillus Sp ASM 18 \\
\hline SPO5 $_{5} 14$ & $2199,30 \%$ & Bacillus velezensis ASM 12 \\
\hline SPO $_{5} 7$ & $1599 \%$ & Bacillus subtilis strain ASM1 \\
\hline CMS 2 & $17 \quad 100 \%$ & Bacillus subtilis strain ASM4 \\
\hline $\mathrm{SPO}_{5} 14$ & $1497 \%$ & Bacillus megaterium strain ASM2 \\
\hline$T_{1-2} 7$ & $299 \%$ & Bacillus pumilusstrain ASM5 \\
\hline$T_{1-21} 1$ & $1897.22 \%$ & Bacillus subtilis strain ASM3 \\
\hline $\mathrm{SPO}_{5} 5$ & $897 \%$ & Bacillus Sp. ASM 16 \\
\hline CMS 12 & $1999.30 \%$ & Bacillus subtilis ASM 21 \\
\hline CMS 6 & $798.64 \%$ & Bacillus Sp CRK \\
\hline CMS 5 & $1399 \%$ & Bacillus subtilis strain ASM6 \\
\hline CMS 4 & $2399.80 \%$ & Bacillus amyloliquefaciens ASM10 \\
\hline CMS 8 & $598.59 \%$ & Bacillus Sp ASM44 \\
\hline CMk 2 & $2797 \%$ & Bacillus sp ASM 7 \\
\hline
\end{tabular}




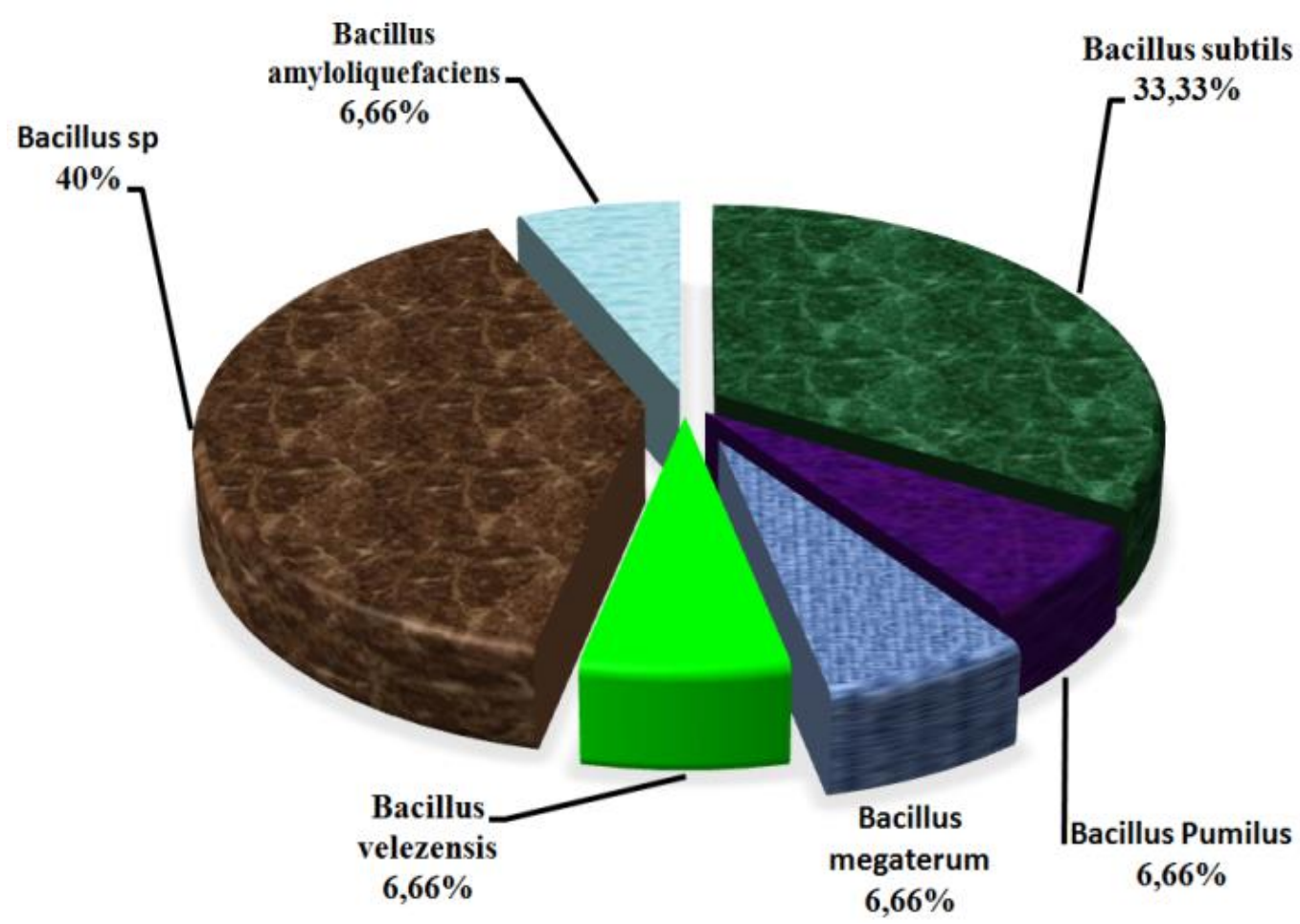

Figure 5. Proportion of isolated species

\subsubsection{Distribution of Isolates by Species after Sequencing and Bioinformatics Analysis}

Sequencing of the gene encoding 16S rRNA has allowed to identified some isolates. Of the 15 isolates analyzed on the Blast database, we counted:6 (40\%) Bacillus sp ; 1 (6,66 \%)Bacillus amyloliquefaciens; 5 (33,33\%)Bacillus subtilis; 1 (6,66 \%) Bacillus pumilus; 1 (6,66\%) Bacillus megaterium; 1 (6,66\%) Bacillus velezensis; 1 (6,66\%). The Figure 5 shows that the bacteria belonging to the subtilis species are the predominant microorganisms $(33.33 \%$ of isolates).

Five of the strains identified by $16 \mathrm{~S}$ rRNA sequencing have been submitted to GenBank, Table 5 shows the different strains and their accession number on Gen BanK

Table 5. strains identified and their Accession number in GenBank

\begin{tabular}{cc}
\hline Identifystrain & Accession number inGenBank \\
\hline Bacillus subtilis strain ASM1 & MK193815.1 \\
\hline $\begin{array}{c}\text { Bacillus megaterium strain } \\
\text { ASM2 }\end{array}$ & MK207437.1 \\
\hline Bacillus subtilis strain ASM3 & MK207434.1 \\
\hline Bacillus subtilis strain ASM4 & MK207436.1 \\
\hline Bacillus pumilusstrain ASM5 & MK207435.1 \\
\hline
\end{tabular}

\subsection{Alignment of the Nucleotide Sequences of the Genes Coding for the 16S Rrna}

Figure 6 shows the multiple alignment of different 16S rRNA gene sequences from strains of Bacillus bacteria isolated from squash. This alignment was done using BioEdiot software.
The $16 \mathrm{~S}$ molecular marker rRNA makes it possible to show a high degree of similarity between homologous sequences.

Analysis of this figure clearly shows that there are areas where the nucleotides have been highly conserved. However, some areas are less similar. by the fact that some indels have been eliminated with the BioEdita program in order to allow a good alignment of the sequences for a possible construction of the phylogenetic tree. The presence of hypervariable regions of the $16 \mathrm{~S}$ rRNA gene provides information specific for the species, and therefore very important for the identification of the latter.

This figure shows that this gene is very conserved and allows the identification of the species and the genus.

\subsection{Phylogenetic Analysis}

Figure 7 shows the phylogenetic tree constructed from the nucleotide sequences of the genes coding for the $16 \mathrm{~S}$ rRNA of bacteria of the genus Bacillus isolated from squash. The counterparts were downloaded in FASTA format via GenBank. The alignment of all the sequences (query sequences and homologs) was done by the BioEdit program. The phylogenetic tree was produced using MEGA version 7 [21]. We used Clostridium tetani NCTC 279 as the outdoor group. Clostridium tetani is a bacterium similar to the genus Bacillus, because they share a certain similarity but do not belong to the same phylogeny group

These sequences were aligned using BioEdit software version 7.0.5.3

Evolutionary relationships of taxa

The analysis involved 28 nucleotide sequences. Codon positions included were $1 \mathrm{st}+2 \mathrm{nd}+3 \mathrm{rd}+$ Noncoding. All positions with gaps and missing data have been eliminated. There were a total of 143 positions in the final dataset. Evolutionary analyzes were carried out in MEGA7 [21]. 
MK207434.1 B. subtilis A.SM3 MIK207435.1 B. pumilus A.SM5 MK207437.1 B. megaterium ASM2 MK207436.1 B. subtilis ASM4 MK193815.1 B. subtilis ASM1 B. amyloliquefaciens A.SM10 Bacillus Sp CRK 29 B. subtilis A.SM21 Bacillus Sp ASM55 B. subtilis strain A.SM6 Bacillus Sp A.SM7 B. velezensis ASM12 Bacillus Sp ASM44 Bacillus Sp ASM16 Bacillus Sp ASM18 MK601669.1 B. pumilus strain C HO917121.1 B. thuringiensis HO694071.1 B. cereus JX683721.1 B. subtilis KC441754.1 Bacillus megaterium MK100782.1 Bacillus pumilus MK156313.1 Bacillus altitudini MK156314.1 Bacillus amylolique NR_029260.1 Clostridium tetani

MK207434.1 B. subtilis ASM3 MK207435.1 B. pumilus A.SM5 MK207437.1 B. megaterium ASM2 MK207436.1 B. subtilis ASM4 MK193815.1 B. subtilis ASM1 B. amy loliquefaciens A.SM10 Bacillus Sp CRK 29 B. subtilis ASM21 Bacillus Sp A.SM55 B. subtilis strain ASM6 Bacillus Sp ASM7 B. velezensis A.SM12 Bacillus Sp ASM44 Bacillus Sp A.SM16 Bacillus Sp A.SM18 MK601669.1 B. pumilus strain C HO917121.1 B. thuringiensis HO694071.1 B. cereus JX683721.1 B. subtilis KC441754.1 Bacillus megaterium MK100782.1 Bacillus pumilus MK156313.1 Bacillus altitudini MK156314.1 Bacillus amylolique NR_029260.1 Clostridium tetani

MK207434.1 B. subtilis ASM3 MK207435.1 B. pumilus ASM5 MK207437.1 B. megaterium ASM2 MK207436.1 B. subtilis ASM4 MK193815.1 B. subtilis ASM1 B. amyloliquefaciens ASM10 Bacillus Sp CRK 29 B. subtilis A.SM21 Bacillus Sp A.SM55 B. subtilis strain ASM6 Bacillus Sp ASM7 B. velezensis ASM12 Bacillus Sp ASM44 Bacillus Sp ASM16 Bacillus Sp ASM18 MK601669.1 B. pumilus strain C HO917121.1 B. thuringiensis HO694071.1 B. cereus JX683721.1 B. subtilis KC441754.1 Bacillus megaterium MK100782.1 Bacillus pumilus MK156313.1 Bacillus altitudini MK156314.1 Bacillus amylolique NR 029260.1 Clostridium tetani
GGCGGACGGGTGAGTAACACGTGGGAACCTGCCTGTAAGACTGGGATAACTCCGGGAAACCGGGGCTAATACCGGATGGTT GGCGGACGGGTGAGTAACACGTGGGAACCTGCCTGTAAGACTGGGATAACTCCGGGAAACCGGAGCTAATACCGGATAGT"T GGCGGACGGGTGAGTAACACGTGGGAACCTGCCTGTAAGACTGGGATAACTTCGGGAAACCGAAGCTAATACCGGAAAGGA GGCGGACGGGTGAGTAACACGTGGGAACCTGCCTGTAAGACTGGGATAACTCCGGGAAACCGGGGCTAATACCGGATGGTT GGCGGACGGGTGAGTAACACGTGGGAACCTGCCTGTAAGACTGGGATAACTCCGGGAAACCGGGGCTAATACCGGATGGTT GGCGGACGGGTGAGTAACACGTGGGAACCTGCCTGTAAGACTGGGATAACTCCGGGAAACCGGGGCTAATACCGGATGGTT' GGCGGACGGGTGAGTAACACGTGGGAACCTGCCTGTAAGACTGGGATAACTCCGGGAAACCGGGGCTAATACCGGATGGTT GGCGGACGGGTGAGTAACACGTGGGAACCTGCCTGTAAAGACTGGGATAAACTCCGGGAAACCGGGGCTAATACCGGATGGT"T GACGGGCGGGTGTACAAGGCCCGGGAACGTATTCACCGCGGCATGCTGATCCGCGATTACTAGCGATTCCAGCTTCACGCA GACGGGCGGGTGTACAAGGCCCGGGAACGTATTCACCGCGGCATGCTGATCCGCGATTACTAGCGATTCCAGCTTCACGCA GGCGGACGGGTGAGTAACACGTGGGAACCTGCCCATAAGACTGGGATAACTCCGGGAAACCGGGGCTAATACCGGATAACA GGCGGACGGGTGAGTAACACGTGGGAACCTGCCTGTAAGACTGGGATAACTCCGGGAAACCGGGGCTAATACCGGATGGTT GGCGGACGGGTGAGTAACACGTGGGAACCTGCCTGTAAAGACTGGGATAACTCCGGGAAACCGGGGCTAATACCGGATGGTT GACGGGCGGGTGTACAAGGCCCGGGAACGTATTCACCGCGGCATGCTGATCCGCGATTACTAGCGATTCCAGCTTCACGCA GGCGGACAGGTGAGTAACACGTGGGAACCTGCCTGTAAGACTGGGATAACTCCGGGATACCGGGGCTAATATCGGATGGTT GGCGGACGGGTGAGTAACACGTGGGAACCTGCCTGTAAGACTGGGATAACTCCGGGAAACCGGAGCTAATACCGGATAGTT GGCGGACGGGTGAGTAACACGTGGGAACCTGCCCATAAAACTGGGATAACTCCGGGAAA_CCGGGGCTAATACCGGATAACA GGCGGACGGGTGAGTAACACGTGGGAACCTGCCCATAAAGACTGGGATAACTCCGGGAAACCGGGGCTAATACCGGATAACA GGCGGACGGGTGAGTAACACGTGGGAACCTGCCTGTAAGACTGGGATAACTCCGGGAAACCGGGGCTAATACCGGATGGTT GGCGGACGGGTGAGTAACACGTGGGAACCTGCCTGTAAGACTGGGATAACTTCGGGAAACCGAAGCTAATACCGGATAGGA GGCGGACGGGTGAGTAACACGTGGGAACCTGCCTGTAAGACTGGGATAACTCCGGGAAACCGGAGCTAATACCGGATAGTT GGCGGACGGGTGAGTAACACGTGGGAACCTGCCTGTAAGACTGGGATAACTCCGGGAAACCGGAGCTAATACCGGATAGTT' GGCGGACGGGTGAGTAACACGTGGGAACCTGCCTGTAAGACTGGGATAACTCCGGGAAACCGGGGCTAATACCGGATGGT"T GAGAGTTTGATCCTGGCTCAGGACGAACGCTGGCGGCGTGCTTAACACATGCAAGTCGAGCGATGAAGCTTCCTTCGGGAA

AACATAAAAGGCTTCGGCTACCACTTACAGATGGACCCGCGGCGCATTAGCTAGTTGGTGAGGTAACGGCTCACCAAGGCG AGGATGAAAAGGTTTCGGCTGTCACTTACAGATGGACCCGCGGCGCATTAGCTAGTTGGTGAGGTAACGGCTCACCAAGGCG TGATTGAAAGGTTTCGGCTATCACTTACAGATGGGCCCGCGGTGCATTAACTATTTGG-GAGGTAACGGCTCACCAAGGCA AACATAAAAGGCTTCGGCTACCACTTACAGATGGACCCGCGGCGCATTAGCTAGTTGGTGAGGTAACGGCTCACCAAGGCG AACATAAAAGGCTTCGGCTACCACTTACAGATGGACCCGCGGCGCATTAGCTAGTTGGTGAGGTAACGGCTCACCAAGGCA AACATAAAAAGGCTTCGGCTACCACTTACAGATGGACCCGCGGCGCATTAGCTAGTTGGTGAGGTAACGGCTCACCAAGGCA AACATAAAAGGCTTCGGCTACCACTTACAGATGGACCCGCGGCGCATTAGCTAGTTGGTGAGGTAACGGCTCACCAAGGCG AACATAAAAGGCT"TCGCTACCACTTACAGATGGACCCGCGGCGCATTAGCTAGTTGGTGAGGTAACGGCTCACCAAGGCG GAACTGAGAAGATTTGGGATTGGCTTAACCTCGGTTTCGCTGCCCTTTGTTCTGCCATTGTAGCAACGTGTGGCCCATGTC GAACTGAGAAGATTTGGGATTGGCTTAAACCTCGGTTTCGCTGCCCTTTGTTCTGCCATTGTAGCAACGTGTGGCCCAGGTC AATTGAAAGGGCTTCGGCTGTCTCT"TATGGATGGACCCGCGTCTCATTATCTAGTCCTCGCAACGGCCCTCCCGTCACGCT TATCTACTAGATT-TCTCTTTTCTTTGGCCTGGGACT-TATGTCCTTCT-TTTT"TATCCTCACAACGCACCCCCGCTCTGAT"T AATATAAATAGTTCTGATCTCTATT'TATAGAGGGACCCTCCGTTCCTTACT'TACCCATCTTGCTTATGGT"TATTGTGTAT GAACTGAGAAGA.TTTGGGATTGGCTAAACCTCGGTCTCGCAGCCCTTTGTTCTGCCATTGTAGCTACGTGTGGCCCAGGTC AACCAAAAAGGCTTGTTATTGCCTT"TATCCTTGGCCTAGTCGCTTATTGTGTGGTCTCTGCACCCTCACTCTGCTCTCTCC AGGATGAAAGGTTTCGGCTGTCACT"ACAGATGGACCCGCGGCGCATTAGCTAGTTGGTGAGGTAACGGCTCACCAAGGCG AAATTGAAAGGCTTCGGCTGTCACTTATGGATGGACCCGCGTCGCATTAGCTAGTTGGTGAGGTAACGGCTCA.CCAAGGCA AAATTGAAAGGCTTCGGCTGTCACTTATGGATGGACCCGCGTCGCATTAGCTAGTTGGTGAGGTAACGGCTCACCAAGGCA AACATAAAAGGCTTCGGCTACCACTTACAGATGGACCCGCGGCGCATTAGCTAGTTGGTGAGGTAACGGCTCACCAAGGCA TGATTGAAAGGTTTCGGCTATCACTTACAGATGGGCCCGCGGTGCATTAGCTAGTTGGTGAGGTAACGGCTCACCAAGGCA AGGATGAAAGGTTTCGGCTGTCACTTACAGATGGACCCGCGGCGCATTAGCTAGTTGGTGAGGTAACGGCTCACCAAGGCG AGGATGAAAGGTTTCGGCTGTCACTTACAGATGGACCCGCGGCGCATTAGCTAGTTGGTGAGGTAACGGCTCACCAAGGCG AACATAAAAGGCTTCGGCTACCACTTACAGATGGACCCGCGGCGCATTAGCTAGTTGGTGAGGTAATGGCTCACCAAGGCA GTGAGTAACACAGTGGGCAACCTGCCTCAAAGAGGGGAATAGCCCTCCGAAAGGAGGATTAATACCGCATAAAGTTAAGGT

(1) CACGGGAGGCAGGTAGGGAATCTTCCGCAATGGAC GAGAGGGTGATCGGCCACACTGGGACTGAGACACGGCCCAGACTCCTACGGGAGGCAGGTAGGGAATCTTCCGCAATGGAC GAGAGGGTGATCGGCCACACTGGGACTGAGACACCGCCCACACTTTTTCGGGAGGCAGGTAGGGAAT-TTCCGCAATGGAC GAGAGGGTGATCGGCCACACTGGGACTGAGACACGGCCCAAACTCCTACGGGAGGCAGGTAGGGAATCTTCCGCAATGGAC GAGAGGGTGATCGGCCACACTGGGACTGAGACACGGCCCAGACTCCTACGGGAGGCAGGTAGGGAATCTTCCGCAATGGAC GAGAGGGTGATCGGCCACACTGGGACTGAGACACCGCCCAGACTCCTACGGGAGGCAGGTAGGGAATCTTCCGCAATGGAC GAGAGGGTGATCGGCCACACTGGGACTGAGACACGGCCCAGACTCCTACGGGAGGCAGGTAGGGAATCTTCCGCAATGGAC GAGAGGGTGATCGGCCACACTGGGACTGAGACACGGCCCAGACTCCTACGGGAGGCAGGTAGGGAATCTTCCGCAATGGAC

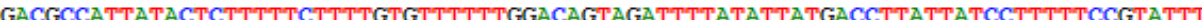
GACGTCATCCCCTCCTCTCCGGTTTGTCTCTCATAGTCCAACGACGCTGGTCCACGAACCTATGGTTGTGTCTAAGTGTTT ATGATGATCTTGT'TCATTCCACTGCCCCCCTCGCCCCTTTCTCTCTTTTATAGT"TCAGTTTT"TT"TCCCTCGCCCTTTCT"T

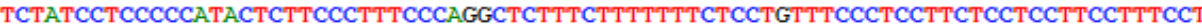
GATTAGCTAAATGACCTTACCTGTCGCCCTTTACTCCTTTTATTACCATGGGGGGTGGTTGAAAATTTTACGTTTTTATC GACGTCATCCCCACCTCTCCGGTTTGTCCCTTAGAGCCCAACGAATGCAGTCAACCACACTACGGTTCGCTTTAAGTCATT ATCAGCCTAGCT"TCAAAAAATCTAATTCCCTTACCTCTTTATTTTCTCCCTCGCTCCATTCA.ATATTCTTTGTTCTGAATT GAGAGGGTGATCGGCCACACTGGGACTGAGACACGGCCCAGACTCCTACGGGAGGCAGGTAGGGAATCTTCCGCAATGGAC GAGAGGGTGATCGGCCACACTGGGACTGAGACACGGCCCAGACTCCTACGGGAGGCAGGTAGGGAATCTTCCGCAATGGAC GAGAGGGTGATCGGCCACACTGGGACTGAGACACGGCCCAGACTCCTACGGGAGGCAGGTAGGGAATCTTCCGCAATGGAC GAGAGGGTGATCGGCCAAACTGGGACTGAGACACGGCCCAGACTCCTACGGGAGGCAGGTAGGGAATCTTCCGCAATGGAC GAGAGGGTGATCGGCCACACTGGGACTGAGACACGGCCCAGACTCCTACGGGAGGCAGGTAGGGAATCTTCCGCAATGGAC GAGAGGGTGATCGGCCACACTGGGACTGAGACACGGCCCAGACTCCTACGGGAGGCAGGTAGGGAATCTTCCGCAATGGAC GAGAGGGTGATCGGCCACACTGGGACTGAGACACGGCCCAGACTCCTACGGGAGGCAGGTAGGGAATCTTCCGCAATGGAC GAGAGGGTGATCGGCCACACTGGGACTGAGACACCGCCCAGACTCCTACGGGAGGCAGGTAGGGAATCTTCCGCAATGGAC AAAGGAGTAATCTGCTTTGAGATGGGCCCGCGCCCCATTAGCTATTTGGTAAGGTAATCTTACCAAGGCGACGTAGGGTAG

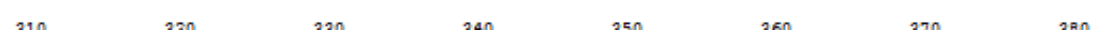

Figure 6. part of the Multiple Alignment of genes encoding 16S rRNA in 24 strains including 9 homologous sequences uploaded to GenBank and 15 request sequences from strains isolated from squash 


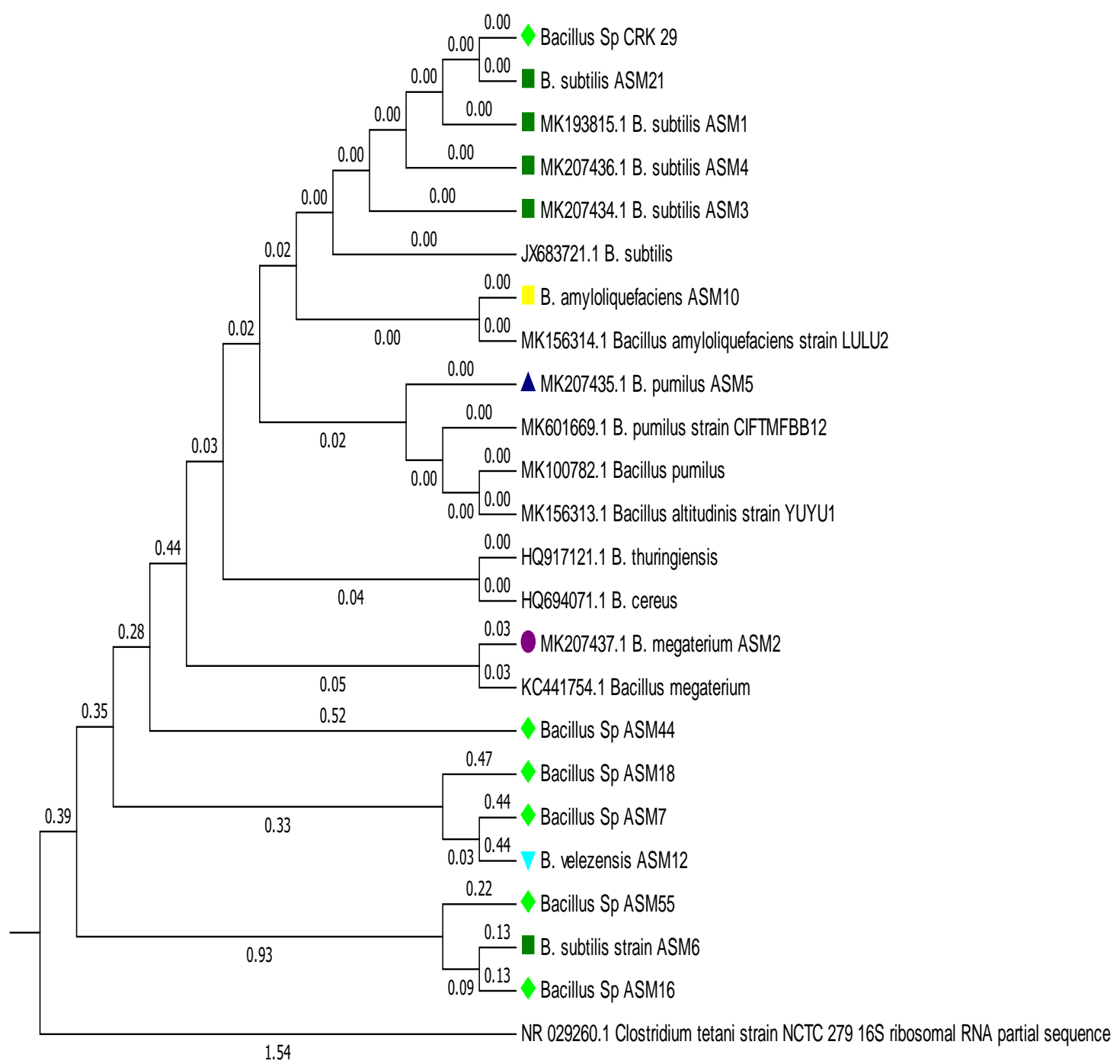

Figure 7. Phylogenetic tree constructed from the alignment of the nucleotide sequences of the genes coding for the 16S rRNA of bacteria of the genus Bacillus isolated from squash.

\section{Discussion}

We found the microorganisms in our food cooked squash wrapped in leaves. The presence of various bacteria in any food (fermented or unfermented) has already been reported [22]. The count on the squash samples (Table 1) shows that the microorganisms are present in the three (3) samples and that the number varies from one sample to another (see Table 1). Our results are similar to those of [23]. Who, working on another food, the fermented chili pepper also showed that the microorganisms varied in number from one sample to another.

A total of 60 isolates were characterized. The microscopic examination made it possible to distinguish variable characteristics. Two forms of bacteria have been characterized, coccis and rods. Rod shapes are more abundant than spherical shapes. They are predominantly gram positive, although some gram negative, catalase positive and negative bacteria have been isolated. In this present work we have retained only the strains which have been isolated with the Mossel medium. The microbial mass of bacteria of the genus Bacillus respectively of the three samples is as follows: $3.5 \pm 1.16 .106 \mathrm{CFU} / \mathrm{g}$ for the sample of the total market, $4.01 \pm 0.85106 \mathrm{CFU} / \mathrm{g}$ for that of the Moukondo market and finally $8.96 \pm 0.60 .106$ $\mathrm{CFU} / \mathrm{g}$ for the sample bought at the Tsèmé market. There is variability in the microbial mass from one sample to another. This variability could be due to hygienic conditions. These results are almost similar to those published by [23] but who worked on a fermented food. The presence of bacteria of the genus Bacillus in fermented foods has already been reported $[21,24,25]$.

Therefore these isolates have been called Bacillus Sp. The presence of the genus Bacillus in food is not surprising, since several studies have reported their presence although most studies have been carried out on fermented foods, it is the case de du NtobaMbodi in Congo Brazzaville [21,26,27], Ugba in Nigeria [28] for is quoted only that.

The purpose of this study was to molecularly identify bacteria belonging to the genus Bacillus present in squash. Amplification and sequencing of the gene encoding the 16S rRNA have made it possible to identify five (5) species of bacteria of the Bacillus genus: Bacillus subtilis, Bacillus megaterium, Bacillus pumilus, Bacillus amyloliquefaciens, Bacillus velezensis. This for six (6) 
islets, the species of which has not been determined due to their low identity rate.

Aligning the nucleotide sequences of genes encoding $16 \mathrm{~S}$ rRNA allowed us to build the phylogenetic tree (Figure 7). The results of the sequencing of the gene encoding the $16 \mathrm{~S}$ rRNA shows a close relationship between the different isolates. The arrangement of the branches clearly shows that this tree is divided into two groups: a group containing the genus Bacillus which shares a common ancestor and the external group represented by the strain Clostridium tetani belonging to the genus Clostridium which illustrates well the filiation. The arrangement of the branches in the first part of the tree informs us that the strains are distant from each other in relation to the genus, but this remains very criticized in relation to the corresponding species.

\section{Conclusion}

This work consisted in characterizing on a molecular level the strains of the genus Bacillus of fibrinolytic character isolated from squash. A total of 60 isolates were phenotypically characterized. The study on the demonstration and evaluation of the production of fibrinolytic enzyme showed that these strains have a potential to produce bioactive molecules (protease). Of the 12 strains tested, all of them generated an interesting proteolysis halo.

15 have been identified on the molecular level, the multiple alignment of their rDNA16S sequences has shown that these sequences are very homologous, the phylogenetic tree has confirmed the consistency of the monophyletic group of Bacillus.

The result thus obtained makes it possible to confirm that there is the presence of a proteolytic activity in the squashes.

\section{Acknowledgements}

We give thanks to Dr BELLE MBOU Mireille for helping to contact Macrogen Europe in France for sequencing. We are grateful to Pr BOUKA BIONA and Pr. GOMA-TCHIMBAKALA respectively General Director and Scientific Director of IRSEN at Brazzaville, in Republic of Congo.

\section{References}

[1] Esther Izquierdo alegre. les proteines bacteriennes en tant que biomarqueurs de l'activite probiotique soute.2009.

[2] Aughan, H., \& Van der Auwer, G. Bacillus taxonomy in the genomic era finds phenotypes to be essential though often misleading. Infection, Genetics and Evolution ,2011, 789-797

[3] Euzéby, J.P. Dictionnaire de Bactériologie Vétérinaire. http://www.bacterio.cict.fr.2002.

[4] Jay, J.M., Loessner M.J., Golden DA. Modern Food Microbiology. 7. New York: Springer Science + Business Media2005.

[5] Sonenshein, A. L., Hoch, J. A., \& Losick, R. Bacillus subtilis. and other Gram positive bacteria. Biochemistry, physiology and molecuar genetics. 2002

[6] Peng, M. Y., Yang, X., \& Zhang, Y. Microbial fibrinolytic enzymes : an overview of source, production, properties, and thrombolytic activity in vivo, 2005, 126-132. https://doi.org/10.1007/s00253-005-0159-7

[7] AFNOR. Microbiologie: Directives générales pour le dénombrement de Bacillus cereus. Paris: AFNOR NF ISO, 1994 7932. 203-2017

[8] Austin, D.A, and Baker, J.H. 1988. Fate of bacteriaingested by larvae of thefreshwatermayfly, Ephemeradanica, Micro Fcol, 15: 323-332.

[9] Dahou, A., Homrani, A., \& Medjahed, F. B. M. La microflore lactique $d$ ' un fromage traditionnel Algérien «type $\mathrm{j}$ ' ben»: connaissance des écosystèmes microbiens laitiers locaux et de leurs rôles dans la fabrication des fromages Résumé, 2015, 11(6), $1-13$.

[10] Said, Z. souches lactiques autochtones isolées du lait de chèvres du Nord du Maroc Elaboration d' un fromage de chèvre semiaffiné à partir d' une sélection de souches lactiques autochtones isolées du lait de chèvres du Nord du Maroc, (June)2013.

[11] Puri, S., Beg, Q. K., \& Gupta, R.. Optimization of Alkaline Protease Production from Bacillus $\mathrm{sp}$. by Response Surface Methodology, 2002, 44, 286-290. https://doi.org/10.1007/s00284001-0006-8

[12] Mabika, S., Faly, A., Moyen, R., Nguimbi, E., Ahombo, G., Ampa, R., ... Kobawila, S. C. Production , Partial Purification and Based SDS-PAGE Profiles of Caseinolytic Enzyme in two Bacillus Strains Isolated from Fermented Cassava leaves “ Ntoba mbodi " in Congo Brazzaville, 2017, 11(March), 77-86.

[13] Nguimbi, E., Ahombo, G., Moyen, R., Ampa, R., Vouidibio, A., Nina, E., ... Louembe, D. Optimization of Growth , Fibrinolytic Enzyme Production and PCR Amplification of Encoding Fibrinolytic Enzyme Gene in Bacillus amyloliquefaciens Isolated from Ntoba mbodi at Brazzaville, 2014, 3(11), 2799-2803.

[14] Wang SH, Zhang C, Yang YL, M. Diao, Bai MF . Projection de haute enzyme fibrinolytique production souche et la caractérisation de l'enzyme fibrinolytique produite à partir de Bacillus subtilis LD 8547. J. mondiale Microbiol. Biotechnol, 7: .Epub. 2007

[15] Afifah, D. N., Sulchan, M., Syah, D., Suhartono, M. T., \& Kim, J. H. (). Purification and Characterization of a Fibrinolytic Enzyme from Bacillus pumilus 2 . g Isolated from Gembus , an Indonesian Fermented Food, 2014, 19(August), 213-219.

[16] Weisburg, W. G., Barns, S. M., Pelletier, D. A., \& Lane, D. J. (). 16S Ribosomal DNA Amplification for Phylogenetic Study, 1991, 173(2), 697-703.

[17] Rouhou, C. Évaluation des classifications phylogénétiques des bacillaceae basées sur les gènes de L' opéron rrn et de gènes de ménage par mouna cheikh Rouhou décembre 2006.

[18] Altschul , F. S., Gish, W., Miller, W., Myers, W. E., and Lipman, J. D. Basic Local AlignmentSearch Tool. J. Mol. Biol. 1990, 215, 403-410

[19] Ennadir, J., Hassikou, R., Askari, G. Al, Arahou, M., Bouazza, F. Amallah, L., ... V-agdal, U. M. Caractérisation phénotypique et génotypique des bactéries lactiques isolées des farines de blé d ' origine marocaine ( Phenotypic and genotypic characterization of lactic acid bacteria isolated from wheat flour from Morocco ), 2014, 5(4), 1125-1132.

[20] Drancourt, Bollet, Carlioz, Martelin, Gayral, \&Raoult, 2000

[21] Kumar S., Stecher G., and Tamura K. MEGA7: Molecular Evolutionary GeneticsAnalysis version 7.0 for biggerdatasets. Molecular Biology and Evolution 2016, 33: 1870-1874.

[22] Louembé, D., Kobawila, S. C., Kalou, G. B., \& Kéléké, S. Etude microbiologique des feuilles fermentées de manioc: "Ntoba Mbodi ," 2003, 106-111.

[23] Mokemiabeka, N. S., Kayath, C. A., Nguimbi, E., Augustin, A. Guy, A., Eboungabeka, M., ... Botteaux, A. Microbiological and biochemical assessment of crushed red pepper from Capsicum frutescens preserved in jars and manufactured in local markets in Republic of Congo, 2016, 4(October), 1-10.

[24] Ouoba, I., Mbozo, A. B. V., Thorsen, L., Anyogu, A., Nielsen, D. S., Kobawila, S. C., \& Sutherland, J. P. (). Lysinibacillus louembei sp . nov ., a spore-forming bacterium isolated from Ntoba Mbodi alkaline fermented leaves of cassava from the Republic of the Congo, 20154256-4262. https://doi.org/10.1099/ijsem.0.000570

[25] Sumi, H., Hamada, H., Tsushima, H., Mihara, H., \& Muraki, H.. Short Communications A novel fibrinolytic enzyme (nattokinase ) in the vegetable cheese Natto; a typical and popular soybean food in the Japanese diet Short Communications A survey of 3-dehydroretinal as a visual pigment chromophore in various 
species of crayfish and other freshwater crustaceans, 1987, 43, 1110-1111.

[26] Vouidibio, A. B., Kobawila, S. C., Anyogu, A., Awamaria, B., Louembe, D., Sutherland, J. P., \& Ouoba, L. I. I. (2017). Investigation of the diversity and safety of the predominant Bacillus pumilus sensu lato and other Bacillus species involved in the alkaline fermentation of cassava leaves for the production of Ntoba Mbodi. Food Control, 82, 154-162. https://doi.org/10.1016/j.foodcont.2017.06.018

[27] Nayra, E., Thorsen, L., Glover, R., Pearl, V., \& Jespersen, L. International Journal of Food Microbiology Identi fi cation of
Bacillus species occurring in Kantong, an acid fermented seed condiment produced in Ghana, 2014, 180, 1-6. https://doi.org/10.1016/j.ijfoodmicro.2014.03.028

[28] Ahaotu, I., Anyogu, A., Njoku, O. H., Odu, N. N., Sutherland, J. P., \& Ouoba, L. I. I. International Journal of Food Microbiology Molecular identi fi cation and safety of Bacillus species involved in the fermentation of African oil beans (Pentaclethra macrophylla Benth) for production of Ugba. International Journal of Food Microbiology, 2013, 162(1), 95-104.

https://doi.org/10.1016/j.ijfoodmicro.2013.01.001

(C) The Author(s) 2020. This article is an open access article distributed under the terms and conditions of the Creative Commons Attribution (CC BY) license (http://creativecommons.org/licenses/by/4.0/). 